\title{
Surgical left ventricular remodeling leads to better long-term survival and exercise tolerance than coronary artery bypass grafting alone in patients with moderate ischemic cardiomyopathy
}

\author{
Omer Dzemali, MD, Petar Risteski, MD, Farhad Bakhtiary, MD, Eduard Singer, Andreas Zierer, MD, \\ Peter Kleine, MD, PhD, and Anton Moritz, MD, PhD
}

\begin{abstract}
Objectives: Optimal treatment strategies for patients with ischemic cardiomyopathy and moderately reduced left ventricular function remain controversial. We assessed the early and midterm outcomes after surgical revascularization alone versus revascularization and additional left ventricular remodeling in these patients.
\end{abstract}

\begin{abstract}
Methods: Between 2000 and 2003, 285 consecutive patients with coronary artery disease and moderately impaired left ventricular function (ejection fraction $30 \%-40 \%$ ) were surgically treated with coronary artery bypass grafting alone (group $1, \mathrm{n}=165$ ) or open left ventricular remodeling in addition to revascularization (group 2, $\mathrm{n}=120$ ). Preoperatively, the New York Heart Association class, left ventricular ejection fraction, and end-diastolic diameter were comparable. Early and midterm outcomes, hemodynamic performance, and quality of life assessed by Minnesota Quality of Life Questionnaire were evaluated during a mean follow-up period of 70 months.
\end{abstract}

Results: Group 2 patients demonstrated significantly longer ventilation times, higher blood loss, and need for blood transfusion but had significantly lower operative mortality $(4.5 \%$ compared with $8.5 \%$ in group 1$)$. Seven-year follow-up demonstrated survival of $74.3 \% \pm 8.1 \%$ in group 1 versus $84.2 \% \pm 5.4 \%$ in group 2 $(P<.05)$. Follow-up examinations revealed greater improvement of functional class in group 1 with mean $1.7 \pm 0.7$ versus $2.03 \pm 0.8$ in group $2(P<.05)$. Cardiac-related hospital readmissions were comparable $(3.8 \%$ vs $4.1 \%, P=.73)$.

Conclusions: Patients with ischemic cardiomyopathy, in whom surgical ventricular remodeling was possible and performed, experienced more perioperative complications but had superior early and midterm outcome regarding survival, functional class, and quality of life.

Earn CME credits at

http://cme.ctsnetjournals.org
Coronary artery bypass grafting (CABG) has been established as standard therapy for patients with advanced coronary artery disease (CAD). ${ }^{1}$ It has also been extended to patients with ischemic cardiomyopathy, even though impaired left ventricular (LV) function has been shown to adversely affect early and late survival after CABG, especially in patients with heart failure. ${ }^{2-4}$ Survival rates decline in relation to the severity of LV dysfunction.

Surgical LV restoration in treatment of heart failure associated with ischemic ventricular dilatation has been shown to

\footnotetext{
From the Department of Thoracic and Cardiovascular Surgery, Johann Wolfgang Goethe University, Frankfurt am Main, Germany.

Received for publication Sept 7, 2008; revisions received Dec 12, 2008; accepted for publication Feb 1, 2009; available ahead of print April 19, 2009.

Address for reprints: Omer Dzemali, MD, Department of Thoracic and Cardiovascular Surgery, Johann Wolfgang Goethe University, Theodor Stern Kai 7, 60590 Frankfurt am Main, Germany (E-mail: dzemali@em.uni-frankfurt.de).

J Thorac Cardiovasc Surg 2009;138:663-8

$0022-5223 / \$ 36.00$

Copyright (c) 2009 by The American Association for Thoracic Surgery

doi:10.1016/j.jtcvs.2009.02.012
}

improve ventricular function, functional class, and symptoms, with excellent 5-year outcomes. ${ }^{5}$ Many of those reports deal with surgical restoration of severely impaired LV reflected by an LV ejection fraction (LVEF) of less than $30 \%$ and/or severely dilated left ventricles (LV endsystolic volume index greater than $100 \mathrm{~mL} / \mathrm{m}^{2}$ ). Yamaguchi and colleagues ${ }^{6}$ reported 5 -year survival following isolated CABG as low as $53 \%$ in these high-risk patients. Additional $\mathrm{LV}$ restoration led to a significant increase of survival at 5 years up to $90 \%$ in the same patient group. ${ }^{7}$

Due to the superior results, LV restoration procedures have become standard of care in patients with severely impaired ventricular function and ventricular dilatation especially if postinfarct aneurysm formation is demonstrated either by echocardiography, magnetic resonance imaging scanning, or angiography. However, optimal treatment strategies for patients with ischemic cardiomyopathy and only moderate LV dysfunction remain controversial. ${ }^{8,9}$ With respect to the available literature on this issue, there is scarcity of reports on the outcomes of combined $\mathrm{LV}$ restoration with CABG in patients with ischemic cardiomyopathy and moderate LV dysfunction.

The following retrospective study aims to assess the early and midterm outcomes after surgical revascularization alone versus $\mathrm{LV}$ remodeling combined with revascularization in 


\section{Abbreviations and Acronyms \\ $\mathrm{CABG}=$ coronary artery bypass grafting \\ $\mathrm{CAD}=$ coronary artery disease \\ $\mathrm{LV}=$ left ventricular \\ LVEF $=$ left ventricular ejection fraction \\ NYHA $=$ New York Heart Association}

patients with ischemic cardiomyopathy and moderately reduced LV function.

\section{PATIENTS AND METHODS}

For purposes of this study, we analyzed medical records from all patients with chronic stable CAD and ischemic cardiomyopathy (LVEF $30 \%-40 \%$ ), who had operative treatment in our department between March 2000 and May 2003. A total of 285 patients meeting these criteria were included in the study and further divided into 2 groups depending on whether a surgical restoration of the impaired LV was not performed (group 1, $\mathrm{n}=165$ ) or performed (group $2, \mathrm{n}=120$ ) in addition to CABG.

Patients with acute preoperative ischemia-related heart failure requiring inotropic support or intra-aortic counterpulsation were excluded from this report. We also did not include patients having redo operations or a concomitant aortic valve procedure.

This retrospective study did not require approval by the Institutional Review Board, as all operative techniques used were considered as established standards.

\section{Patients}

Moderate ischemic cardiomyopathy was defined as at least coronary 2vessel disease and LVEF of $30 \%$ to $40 \%$ and symptoms of heart failure corresponding to New York Heart Association (NYHA) functional class III or IV as recommended. ${ }^{10}$

The preoperative patient demographics are displayed in Table 1. Patients in both groups did not significantly differ except that group 1 had a higher rate of chronic obstructive pulmonary disease and systemic hypertension and group 2 had a higher preoperative cerebrovascular event rate. The majority of patients presented with 3-vessel disease and history of previous myocardial infarction, mostly located at the anterior wall. All patients were in NYHA functional class III or IV. Preoperative NYHA class, LVEF, and end-diastolic diameter were comparable between the 2 groups $(3.2 \pm 0.6,37.7 \% \pm 112 \%$, and $64.1 \pm$ $7.3 \mathrm{~mm}$, respectively, in group 1 vs $3.1 \pm 0.6,38.9 \% \pm 12.1 \%$, and 66.8 $\pm 8.6 \mathrm{~mm}$, respectively, in group 2). More than $40 \%$ of patients in both groups had diabetes with equal distribution of insulin dependency.

\section{Surgical Procedures}

All patients had preoperative left ventriculography and echocardiography for determination of LV volumes and diameters, as well as assessment of mitral valve function and ejection fraction. Measurement of ejection fraction was performed at stable hemodynamic conditions and only in the absence of moderate or severe mitral regurgitation. Still, afterload variations might have interfered with the results. Parameters to identify patients suitable to surgical remodeling were as follows: an echocardiographic dyskinetic or akinetic zone of at least $3 \mathrm{~cm}$ in diameter, ventricular dilatation with LV end-diastolic diameter $>55 \mathrm{~mm}$, and LV thrombus.

All operations were performed by 4 senior surgeons using cardiopulmonary bypass, tepid blood cardioplegia, and moderate systemic hypothermia $\left(30^{\circ} \mathrm{C}-32^{\circ} \mathrm{C}\right)$. Complete myocardial revascularization as allowed by the quality of coronary arteries with at least 1 arterial graft was performed in all patients. A potentially resectable regional LV impairment was defined as delineated zone of dyskinetic or akinetic anterior LV wall as a consequence
TABLE 1. Preoperative patient demographics

\begin{tabular}{|c|c|c|c|}
\hline Baseline characteristics & $\begin{array}{l}\text { Group 1 } \\
(\mathbf{n}=165)\end{array}$ & $\begin{array}{c}\text { Group 2 } \\
(\mathbf{n}=\mathbf{1 2 0})\end{array}$ & $\begin{array}{r}P \\
\text { valu }\end{array}$ \\
\hline Age (y) & $70.5 \pm 9.8$ & $68.3 \pm 9.76$ & \\
\hline Males (n, \%) & $125(76)$ & $85(71)$ & \\
\hline Chronic renal failure, $\mathrm{n}(\%)$ & $58(35)$ & $35(29)$ & \\
\hline COPD, n $(\%)$ & $58(35)$ & $27(22.5)$ & \\
\hline Systemic hypertension, $\mathrm{n}(\%)$ & $141(85)$ & $83(69)$ & \\
\hline Pulmonary hypertension, $\mathrm{n}(\%)$ & $38(23)$ & $18(15)$ & \\
\hline $\begin{array}{l}\text { Prior cerebrovascular } \\
\text { event, } \mathrm{n}(\%)\end{array}$ & $13(8)$ & $17(14)$ & \\
\hline Morbid obesity, n (\%) & $38(23)$ & $20(17)$ & \\
\hline Diabetes mellitus, n (\%) & $74(45)$ & $52(43)$ & \\
\hline CCS class (mean $\pm \mathrm{SD}$ ) & $2.97 \pm 0.7$ & $3.03 \pm 0.7$ & \\
\hline $\mathrm{CAD}$ involvement (mean $\pm \mathrm{SD})$ & $2.8 \pm 0.5$ & $2.6 \pm 0.7$ & $\mathrm{~N}$ \\
\hline Myocardial infarction, n (\%) & $128(78 \%)$ & $100(83 \%)$ & \\
\hline Anterior wall, n (\%) & $55(33 \%)$ & $51(43 \%)$ & $<$. \\
\hline Posterior wall, n (\%) & $62(38 \%)$ & $38(32 \%)$ & $t$ \\
\hline $\begin{array}{l}\text { Anterior and posterior } \\
\text { wall, } \mathrm{n}(\%)\end{array}$ & $11(7)$ & $11(9)$ & \\
\hline NYHA class (mean $\pm \mathrm{SD})$ & $3.2 \pm 0.6$ & $3.1 \pm 0.6$ & $\mathrm{~N}$ \\
\hline $\mathrm{LVEF}$, mean $\pm \mathrm{SD}(\%)$ & $37.7 \pm 11.2$ & $39.9 \pm 12.1$ & \\
\hline LVEDD, mean \pm SD $(\mathrm{mm})$ & $57.1 \pm 7.3$ & $59.8 \pm 8.6$ & $\mathrm{~N}$ \\
\hline $\operatorname{LVESVI}\left(\mathrm{mL} / \mathrm{m}^{2}\right)$ & $84.2 \pm 16$ & $92.3 \pm 22$ & \\
\hline Moderate or severe & $32(19)$ & $14(12)$ & $\mathrm{N}$ \\
\hline
\end{tabular}

mitral regurgitation

COPD, Chronic obstructive pulmonary disease; $C C S$, Canadian Cardiovascular Society; $C A D$, coronary artery disease; $N Y H A$, New York Heart Association; $L V E F$, left ventricular ejection fraction; $L V E D D$, left ventricular end-diastolic diameter; $L V E S V I$, left ventricular end-systolic volume index; $S D$, standard deviation; $N S$, not significant.

of old myocardial infarction that displayed akinesis or diskinetic bulging as seen in the preoperative angiography or echocardiography. Furthermore, presences of LV mural thrombus as well as history of ventricular tachycardias were further indications. More diffuse scarring without a clear border to the surrounding myocardium was not defined as suitable for resection. In those patients in whom a restoration procedure was performed, a delineated zone of dyskinetic or akinetic anterior LV wall was intraoperatively identified and opened. The nonfunctional myocardium was excised and reconstructed using a modified Dor's technique ${ }^{11}$ for large $L V$ volumes $(n=64)$ or a modified Jatene's technique ${ }^{12}$ for smaller aneurysms $(n=56)$. As a first step, a continuous 3-0 polypropylene purse-string suture placed at the border between viable and scarred myocardium was used to constrict the distal ventricular diameter, in most cases followed by direct closure using polytetrafluoroethylene-armed running suture. If the remodeled ventricular cavity was expected to be too small with this technique, an additional pericardial patch was used to remodel the LV apex. Care was taken to plicate a septal scar when applicable. Subsequently, the mitral valve was approached $(n=32$ in group 1 and $n=34$ in group 2). Mitral repair was performed in all cases of mitral insufficiency greater than $2+$ or annulus dilatation to a diameter of more than $35 \mathrm{~mm}$. Mitral annuloplasty was performed using undersized rings, mostly either Carpentier Edwards Classic or Physio (Edwards LifeSciences, Irvine, Calif). Only 2 valves in each group had to be replaced. If no contraindication was identified, all patients received angiotensin-converting enzyme inhibitors and beta-blockers postoperatively.

\section{Follow-up}

Data were collected retrospectively by means of questionnaires containing the Minnesota Quality of Life Questionnaire ${ }^{13-15}$ mailed to the patients or family practitioners and telephone interviews specifically addressing longterm medication and procedure-related complications. Clinical and 
TABLE 2. Operative data

\begin{tabular}{|c|c|c|c|}
\hline Operative data & $\begin{array}{c}\text { Group 1 } \\
(\mathrm{n}=\mathbf{1 6 5})\end{array}$ & $\begin{array}{c}\text { Group } 2 \\
(\mathrm{n}=\mathbf{1 2 0})\end{array}$ & $\begin{array}{c}P \\
\text { value } \\
\end{array}$ \\
\hline \multicolumn{4}{|l|}{ Procedures } \\
\hline CABG (n) & $133(81 \%)$ & $106(88 \%)$ & NS \\
\hline $\begin{array}{l}\mathrm{CABG}+\text { valve } \\
\text { replacement/repair (n) }\end{array}$ & $32(19 \%)$ & $14(12 \%)$ & NS \\
\hline Bypass grafts (n) & $2.9 \pm 1.1$ & $2.9 \pm 1.0$ & NS \\
\hline Venous grafts (mean $\pm \mathrm{SD}$ ) & $2.2 \pm 0.9$ & $2.1 \pm 0.8$ & NS \\
\hline Arterial grafts (mean $\pm \mathrm{SD}$ ) & $1.12 \pm 0.5$ & $1.15 \pm 0.5$ & NS \\
\hline $\begin{array}{l}\text { Operation time, } \\
\text { mean } \pm \mathrm{SD}(\mathrm{min})\end{array}$ & $200.2 \pm 73.8$ & $214.7 \pm 69.4$ & NS \\
\hline $\mathrm{ECC}$ time, mean $\pm \mathrm{SD}(\min )$ & $103.9 \pm 42.4$ & $109.2 \pm 42.8$ & NS \\
\hline $\begin{array}{l}\text { Crossclamp time, } \\
\text { mean } \pm \mathrm{SD}(\mathrm{min})\end{array}$ & $59.3 \pm 28.6$ & $63.2 \pm 28.4$ & NS \\
\hline \multicolumn{4}{|l|}{ Cardioplegia } \\
\hline Calafiore, $\mathrm{n}(\%)$ & $114(69 \%)$ & $93(78 \%)$ & NS \\
\hline $\begin{array}{l}\text { Cold blood } \\
\quad \text { cardioplegia, n (\%) }\end{array}$ & $53(31 \%)$ & $27(22 \%)$ & NS \\
\hline $\begin{array}{l}\text { Operative blood loss, } \\
\text { mean } \pm \mathrm{SD}(\mathrm{mL})\end{array}$ & $679.1 \pm 473.2$ & $686.6 \pm 455.1$ & NS \\
\hline $\begin{array}{l}\text { Operative transfusion, } \\
\text { mean } \pm \mathrm{SD}(\mathrm{mL})\end{array}$ & $415.0 \pm 436.2$ & $441.6 \pm 412.9$ & NS \\
\hline
\end{tabular}

echocardiographic examinations in our outpatient clinic or by referring cardiologists were performed at 1 and 5 years after discharge. LVEF was calculated using the Simpson formula from biplane apical 4- and 2-chamber views.

Patients were followed for a total of 1615 patient-years. The mean clinical follow-up was $68 \pm 5$ months (range $48-84$ months) and was $100 \%$ complete.

\section{Definitions and Data Analysis}

Early mortality was defined as in hospital death within 30 days after the operation; late mortality was defined as death after this period.

Low cardiac output syndrome was defined as heart index below $2.2 \mathrm{~L}$ $\min ^{-1} \cdot \mathrm{m}^{-2}$. Chronic renal failure was defined as structural or functional abnormalities of the kidney with decreased glomerular filtration rate $(<60 \mathrm{~mL}$ $\left.\cdot \min ^{-1} \cdot 1.73 \mathrm{~m}^{-2}\right)$, manifested by pathologic abnormalities or markers of kidney damage, including abnormalities in the composition of the blood or urine. Statistical analysis of the data was performed by using the Dallal-Wilkinson corrected and Kolmogoroff-Smirnoff test. ${ }^{16}$ If this could be verified due to small deviation of results, differences between both groups were assessed by 2 -sample $t$ tests, the Mann-Whitney $U$ test, analysis of variance, and multiple comparisons by Scheffé method with $95 \%$ confidence limits. ${ }^{16}$ The commercially available statistical software BIAS, packaged for Windows (Version 8.3.8, Epsilon-Verlag, Frankfurt am Main, Germany), was used to perform the statistical analysis. Continuous data are expressed as mean \pm standard deviation, unless indicated otherwise. Categorical data are expressed as frequencies.

Obesity was defined if the body mass index was equal or higher than 30.0 $\mathrm{kg} / \mathrm{m}^{2}$.

Survival was estimated with the standard nonparametric Kaplan-Meier method. ${ }^{17}$ Differences between survival curves were compared using the Breslow test. ${ }^{18}$

\section{RESULTS}

Table 2 summarizes the operative results. The mean operating, cardiopulmonary bypass, and aortic crossclamp times
TABLE 3. Postoperative data

\begin{tabular}{|c|c|c|c|}
\hline & $\begin{array}{c}\text { Group } 1 \\
(\mathrm{n}=165)\end{array}$ & $\begin{array}{c}\text { Group } 2 \\
(\mathbf{n}=\mathbf{1 2 0})\end{array}$ & $\begin{array}{c}P \\
\text { value }\end{array}$ \\
\hline CU time, mean $(\mathrm{d})$ & $3.2 \pm 5.6$ & $3.9 \pm 7.9$ & NS \\
\hline $\begin{array}{l}\text { Ventilation time, } \\
\text { mean (min) }\end{array}$ & $26.1 \pm 34.1$ & $39.7 \pm 66.3$ & $>.05$ \\
\hline IABP insertion, $\mathrm{n}(\%)$ & $30(18.2 \%)$ & $22(18.2 \%)$ & NS \\
\hline $\begin{array}{l}\text { Blood loss postoperatively, } \\
\text { mean } \pm \mathrm{SD}(\mathrm{mL})\end{array}$ & $242.9 \pm 467.8$ & $441.04 \pm 611.94$ & $<.05$ \\
\hline $\begin{array}{l}\text { Transfusion postoperatively, } \\
\text { mean } \pm \mathrm{SD}(\mathrm{mL})\end{array}$ & $243.75(317.68)$ & $118.75(233.33)$ & $>.05$ \\
\hline $\begin{array}{l}\text { Hospitalization time, } \\
\text { mean } \pm \mathrm{SD}(\mathrm{d})\end{array}$ & $11.7 \pm 8.6$ & $12.8 \pm 9.3$ & NS \\
\hline $\begin{array}{l}\text { Serum creatinine, } \\
\quad \text { mean } \pm \mathrm{SD}(\mathrm{mg} / \mathrm{dL})\end{array}$ & $1.46 \pm 0.95$ & $1.47 \pm 0.74$ & NS \\
\hline Serum $\mathrm{CK}$, mean $\pm \mathrm{SD}(\mathrm{U} / \mathrm{L})$ & $901.4 \pm 1547.0$ & $750.1 \pm 791.14$ & NS \\
\hline EF postoperatively (\%) & $42.1 \pm 5.6$ & $48.1 \pm 7.3$ & NS \\
\hline LVEDD, mean $\pm \mathrm{SD}(\mathrm{mm})$ & $57.1 \pm 7.3$ & $53.8 \pm 8.6$ & NS \\
\hline $\operatorname{LVESVI}\left(\mathrm{mL} / \mathrm{m}^{2}\right)$ & $66.2 \pm 16$ & $56.3 \pm 22$ & $<.05$ \\
\hline
\end{tabular}

$I C U$, Intensive care unit; IABP, intra-aortic balloon pump; $S D$, standard deviation $C K$, creatinine kinase; $E F$, ejection fraction; $L V E D D$, left ventricular end-diastolic diameter; $L V E S V I$, left ventricular end-systolic volume index; $N S$, not significant.

did not significantly differ between the groups and averaged to $200.2 \pm 73.8,103.9 \pm 42.4,59.3 \pm 28.6$ minutes in group 1 , respectively, and $214.7 \pm 69.4,109.2 \pm 42.8,63.2 \pm 28.4$ minutes in group 2 , respectively. LV end-systolic volume index was significantly lower in group 2 following the remodeling procedure.

Global systolic function improved early postoperatively. LVEF increased by $4.7 \% \pm 1.2 \%$ in surviving group $1 \mathrm{pa}-$ tients and by $9.7 \% \pm 2.1 \%$ in those of group 2 . This difference in LVEF increase demonstrated a trend in favor of group 2 but failed to reach statistical significance $(P=$ .055). However, the addition of the LV restoration to the myocardial revascularization led to significantly greater reduction of LV end-diastolic diameter as well as systolic volume index in group 2 (Table $3, P<.05$ ).

Group 2 patients had significantly longer ventilation times, higher blood loss, and greater need for postoperative blood transfusion (Table 3). The rate of rethoracotomy did not differ between the groups. Five patients in each group developed low cardiac output early postoperatively. The number of patients with end-stage renal failure amounted to $8(5.2 \%)$ in group 1 and $7(6.1 \%)$ in group 2 . Operative mortality was significantly lower in group $2(4.5 \%)$ compared with group $1(8.5 \%, P<.05)$.

\section{Follow-up}

Figure 1 demonstrates the Kaplan-Meier survival curves for a period of 7 years for the 2 groups comparing patients with an age- and sex-matched German population. At 7 years' follow-up, survival was $74.3 \% \pm 8.1 \%$ in group 1 versus $84.2 \% \pm 5.4 \%$ in group $2(P<.001)$. Long-term 

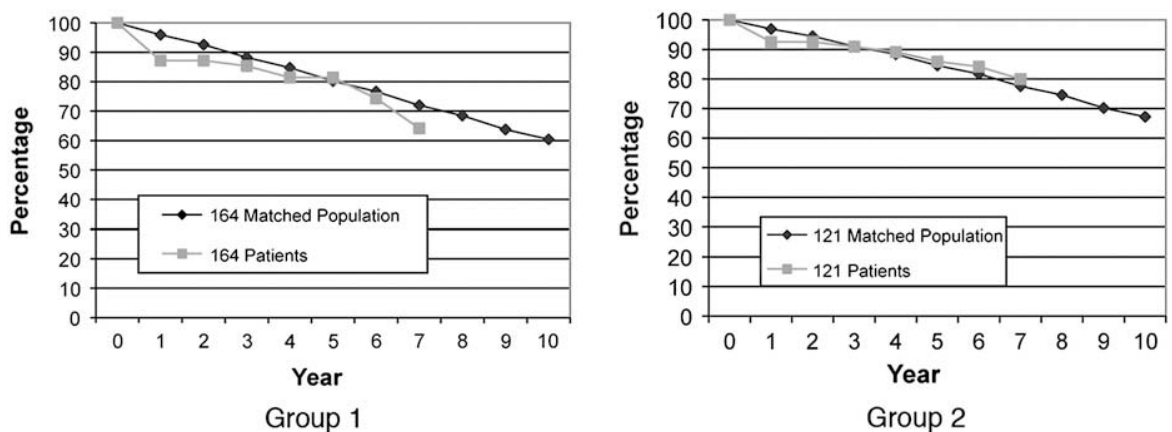

FIGURE 1. Survival curves of the 2 groups. Patients of group 2 (coronary artery bypass grafting + left ventricular LV remodeling) demonstrated superior survival compared with patients of group 1 (coronary artery bypass grafting alone).

outcome of group 2 patients was equal to the matched population (Figure 1). The differences of survival were significantly lower for female compared to male patients (Figure 2, $A$ and $B$ ). Functional class and improvement of exercise tolerance were significantly better for group 2 with mean of $1.7 \pm 0.7$ than for group 1 with a mean of $2.03 \pm 0.8(P<.05)$.

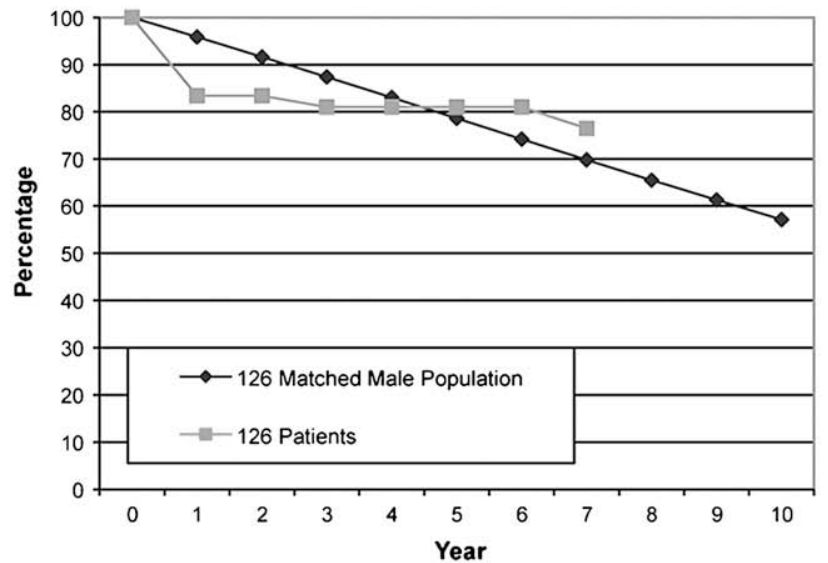

A

Group 1

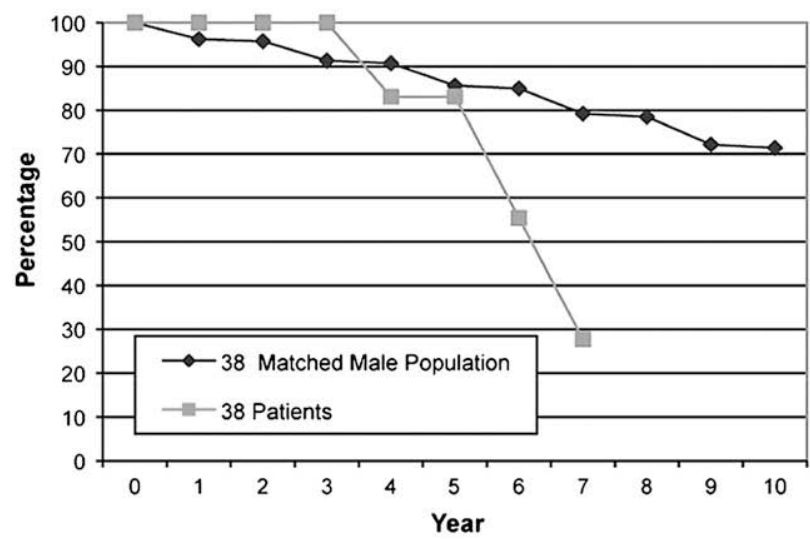

B

Group 1
Overall quality of life assessed by the Minnesota Quality of Life Questionnaire demonstrated a significantly better quality of life for group 2 patients $(13.2 \pm 13.4$ vs $20.2 \pm$ 18 points, $P=.0007$; Figure 3 ).

The differences of Canadian Cardiovascular Society were not significant for group $1(1.1 \pm 4.1)$ and group 2 $(1.2 \pm 4.4)$.

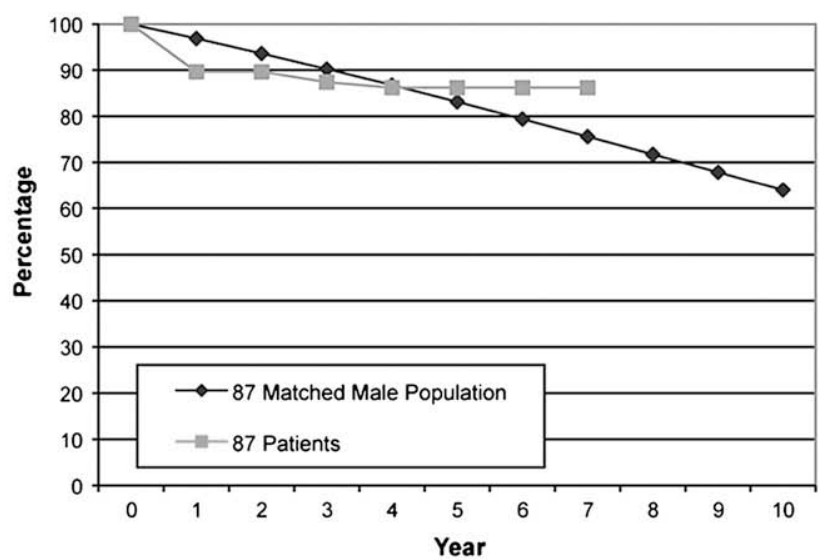

Group 2

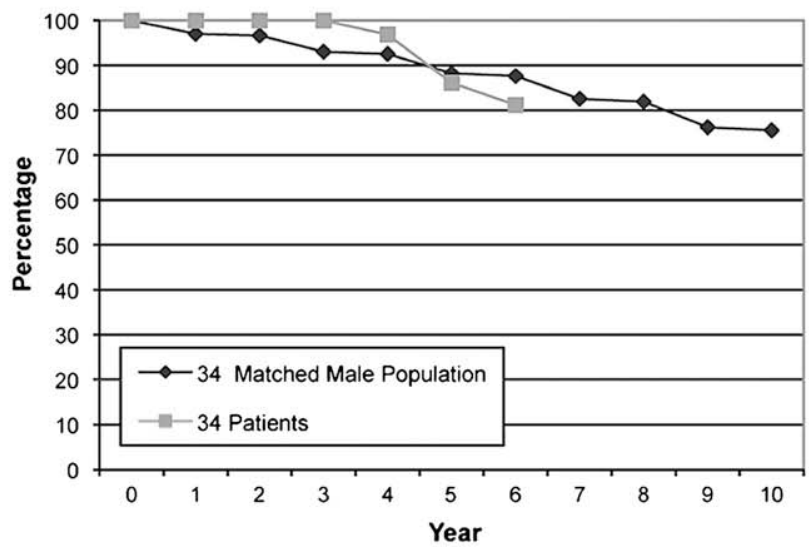

Group 2

FIGURE 2. A and B, Survival curves of the 2 groups separated for gender. Both male and female patients showed improved midterm survival with a more pronounced difference for female patients. 


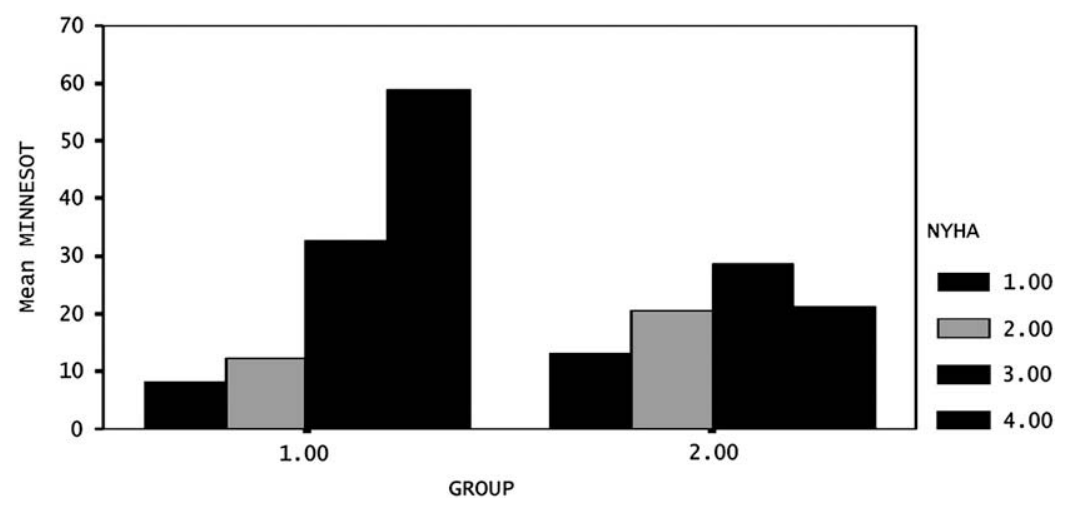

FIGURE 3. Quality of life (QoL) assessed by the Minnesota Quality of Life Questionnaire, which demonstrated a significantly better QoL for group 2 patients $(\mathrm{G} 2=13.2 \pm 13.4$ vs $\mathrm{G} 1=20.2 \pm 18$ points, $P=.0007)$. NYHA, New York Heart Association class.

LVEF increased further during follow-up in both groups, with a significant difference in favor of group 1 (group $1=$ $48.8 \% \pm 7.4 \%$ and group $2=58.9 \% \pm 6.2 \%, P<.05)$.

Cardiac-related hospital readmissions (due to progressive heart failure, progression of CAD, or arrhythmias) were comparable $(3.8 \%$ in group $1 \mathrm{vs} 4.1 \%$ in group 2 , $P=.73)$.

\section{DISCUSSION}

In the current era of early interventional procedures for acute myocardial infarctions with prompt opening of the culprit lesion, thin-walled dyskinetic aneurysm formation has become a less frequent infarct complication. Instead, the resulting grossly akinetic segment retains its near-normal appearance and thickness but poses a long-lasting drive for remote ventricular remodeling. Thus, surgeons nowadays frequently see patients presenting with a moderately impaired LV composed of relatively modest akinetic zones and localized dyskinetic areas or a combination of both. Survival in medically treated patients with ischemic cardiomyopathy is poor, ${ }^{19-21}$ so more aggressive strategies have been promoted in the past decade. Indeed, outcome of surgically treated patients was superior to previous conservative treatment. ${ }^{2,23}$ The opinion among surgeons whether or not one should attempt to restore a moderately impaired left ventricle is controversial; many would leave the geometry undisturbed hoping for CABG alone to improve ventricular function. $^{24,25}$ In this report, we attempted to address this issue and observed the early and midterm outcomes following operative revascularization alone versus LV restoration combined with revascularization in patients with ischemic cardiomyopathy and moderate LV dysfunction.

In our patient cohort, LV remodeling procedures were more likely performed in patients with previous anterior wall infarctions due to well-established operative techniques described for this pathology. ${ }^{11,12}$ Such patients with relatively modest $\mathrm{LV}$ dilatation had a modified Jatene procedure in our institution, and those patients with markedly dilated
LV would be considered candidates for a modified Dor procedure as described above. Ejection fraction did not differ between the 2 groups and therefore did not predict LV remodeling operations. Although only 5 patients in each group developed low cardiac output syndrome, an intra-aortic balloon pump was inserted more frequently, as we liberally tend to mechanically support those patients with borderline output intraoperatively to avoid necessity for high doses of inotropes. No complication from the application and use of intra-aortic balloon counterpulsation was observed. In all these patients, the balloon pump was sufficient to support the circulation, and no further mechanical support was necessary as patients with severely depressed LV function were not included in the study. Regarding the inotrope support regimen in our unit, milrinone has routinely been used as a first-line inotrope, with the dosage adjusted according to frequent measurements of cardiac output. Secondary drugs were epinephrine and dobutamine. This regimen was not different between groups, so it could not account for the differences in operative mortality.

Significantly higher blood loss and greater need for transfusion were seen after ventricular restoration procedures without impairing the remaining postoperative outcome parameters, so the remodeling procedure did not add significant morbidity. The operative mortality was higher than usual in CABG operations. As the mortality was only $4.5 \%$ in the CABG-only procedures, this was partially explained by the high percentage of concomitant mitral procedures. Also, comorbidities led to a mean preoperative European System for Cardiac Operative Risk Evaluation (EuroSCORE) of $8.2 \%$ in group 1 versus $7.9 \%$ in group 2 (difference not statistically significant), so the operative outcome at least matched the patients' risk profiles. Midterm survival and quality of life demonstrated a clear benefit for group 2. Complete revascularization alone exerts some effect on reverse remodeling primarily by revitalizing hibernating myocardium ${ }^{22}$; it is, however, the ventricular restoration that reduces volumes, improves function, and 
ultimately improves survival. Those patients achieved a survival similar to that of a matched German population up to the 7 years' follow-up. On the other hand, female patients having revascularization alone showed markedly inferior results with less than $30 \%$ survival rates after 6 years.

Quality of life could be related to the improvement in NYHA classification for both groups and also demonstrated superior results for the patients following LV restoration procedure. Therefore, our study strongly favors ventricular remodeling operations in patients with moderately impaired LV function, especially female patients, as they did not improve sufficiently if the ventricular dysfunction was not addressed.

During the study period, the impact of cardiac resynchronization therapy in patients with bad ventricular function having cardiac surgery was not established. Consecutively, patients enrolled in this study were not subjected to such therapy. Clearly, many of them would have been observed as candidates for cardiac resynchronization and defibrillator therapy according to the contemporary understanding of this treatment modality.

\section{Limitations of This Study}

This is a nonrandomized, retrospective study of patients who had surgical therapy for ischemic cardiomyopathy.

Ventricular geometry was probably different in the study groups with predominance of defined akinetic or dyskinetic areas in group 2 . The outcome of patients with akinetic versus dyskinetic anterior walls was not analyzed separately, as the patient files did not discriminate these 2 findings in all cases. So no conclusion can be drawn as to whether patients with dyskinetic areas behaved differently from those with akinetic wall areas.

Our patients did not have coronary angiography postoperatively. Graft failure does influence LV remodeling unfavorably and therefore the clinical outcomes after surgical treatment for ischemic cardiomyopathy.

\section{References}

1. Hamm CW, Reimers J, Ischinger T, Rupprecht HJ, Berger J, Bleifeld W. A randomized study of coronary angioplasty compared with bypass surgery in patients with symptomatic multivessel coronary disease. German Angioplasty Bypass Surgery Investigation (GABI). N Engl J Med. 1994;331:1037-43.

2. Myers WO, Blackstone EH, Davis K, Foster ED, Kaiser GC. CASS Registry long term surgical survival. Coronary Artery Surgery Study. J Am Coll Cardiol. 1999; 33:488-98.

3. Argenziano M, Spotnitz HM, Whang W, Bigger JT Jr, Parides M, Rosa EA. Risk stratification for coronary bypass surgery in patients with left ventricular dysfunction: analysis of the coronary artery bypass grafting patch trial database. Circulation. 1999; 100:II119-24.

4. Baker DW, Jones R, Hodges J, Massie BM, Konstam MA, Rosa EA. Management of heart failure. III. The role of revascularization in the treatment of patients with moderate or severe left ventricular systolic dysfunction. JAMA. 1994;272: 1528-34.

5. Athanasuleas CL, Buckberg GD, Stanley AW, Siler W, Dor V, DiDonato M, et al. Surgical ventricular restoration in the treatment of congestive heart failure due to post-infarction ventricular dilation. J Am Coll Cardiol. 2004;44:1439-45.

6. Yamaguchi A, Ino T, Adachi H, Murata S, Kamio H, Okada M, et al. Left ventricular volume predicts postoperative course in patients with ischemic cardiomyopathy. Ann Thorac Surg. 1998;65:434-8.

7. Yamaguchi A, Adachi H, Kawahito K, Murata S, Takashi I. Left ventricular reconstruction benefits patients with dilated ischemic cardiomyopathy. Ann Thorac Surg. 2005;79:456-61

8. O'Connor CM, Velazquez EJ, Gardner LH, Smith PK, Newman MF, Lamdolfo KP, et al. Comparison of coronary artery bypass grafting versus medical therapy on long-term outcome in patients with ischemic cardiomyopathy (a 25-year experience from the Duke Cardiovascular Disease Databank). Am J Cardiol. 2002;90:101-7.

9. Kleikamp G, Posival H, Minami K, El-Banayosy A, Körfer R. Ischemic cardiomyopathy-revascularization vs. transplantation. Eur J Cardiothorac Surg. 1997;11(Suppl):S1-4.

10. Felker GM, Shaw LK, O'Connor CM. A standardized definition of ischemic cardiomyopathy for use in clinical research. $J$ Am Coll Cardiol. 2002;39:210-8.

11. Dor V, Kreitmann P, Jourdan J. Interest of physiological closure (circumferential plasty on contractile areas) of left ventricle after resection and endocardectomy for aneurysms or akinetic zones. Comparison with classical technique about a series of 209 left ventricular resections. J Cardiovasc Surg (Torino). 1985;26:73 (Abstract).

12. Jatene AD. Left ventricular aneurysmectomie: resection and reconstruction. J Thorac Cardiovasc Surg. 1985;89:321-1.

13. Rector TS, Francis GS, Cohn JN. Patients' self-assessment of their congestive heart failure. Part 1. Patient perceived dysfunction and its poor correlation with maximal exercise tests. Heart Fail. 1987;3:192-6.

14. Rector TS, Kubo SH, Cohn JN. Patients' self-assessment of their congestive heart failure. Part 2: Content, reliability and validity of a new measure, the Minnesota Living with Heart Failure questionnaire. Heart Fail. 1987;3:198-209.

15. Rector TS. A conceptual model of the quality of life in relation to heart failure. J Card Fail. 2005;11:173-6.

16. Sachs L. Angewandte Statistik, Chapter 36. 8th ed. Berlin: Springer-Verlag; 1997. p. $345-56$.

17. Kaplan El, Meier P. Nonparametric estimation from incomplete observations. J Am Stat Assoc. 1958;53:457-81.

18. Breslow N. Covariance analysis of censored survival data. Biometrics. 1974;30: 89-99.

19. The CONSENSUS Trial Study Group. Effects of enalapril on mortality in severe congestive heart failure: results of the Cooperative Scandinavian Enalapril Survival Study (CONSENSUS). N Engl J Med. 1987;316:1429-35.

20. The Acute Infarction Efficacy (AIRE) Study Investigators. Effect of ramipril on mortality and morbidity of survivors of acute myocardial infarction with clinical evidence of heart failure. Lancet. 1993;342:821-8.

21. Packer M, Coats AJ, Fowler MB, Katus HA, Krum H, Mohacsi P, et al. Effect of carvedilol on survival in severe chronic heart failure. N Engl J Med. 2001;344: 1651-8.

22. Bell MR, Gersh BJ, Schaff HV, Hoömes DR Jr, Fisher LD, Alderman EL, et al. Effect of completeness of revascularization on long-term outcome of patients with three-vessel disease undergoing coronary artery bypass surgery: a report from the Coronary Artery Surgery Study (CASS) registry. Circulation. 1991;84(Suppl 3): 260-7.

23. Kleinkamp G, Maleszka A, Reiss N, Stuttgen B, Korfer R. Determinants of mid- and long-term results in patients after surgical revascularization for ischemic cardiomyopathy. Ann Thorac Surg. 2003;75:1406-12.

24. Hata M, Raman JS, Storer M, Matalanis G, Rosalion A, Buxton BF, et al. The mid-term outcome of geometric endoventricular repair for the patients with ischemic left ventricular dysfunction. Ann Thorac Cardiovasc Surg. 2003;9:241-4.

25. Di Donato M, Frigiola A, Benhamouda M, Menicanti L. Safety and efficacy of surgical ventricular restoration in unstable patients with recent anterior myocardial infarction. Circulation. 2004;110(11 Suppl. 1):II169-73 (Review). 